\title{
Analysis of the velocity distribution in the UVC module
}

\author{
Sławomira Dumała ${ }^{1, *}$, Mariusz Skwarczyński ${ }^{2}$, and Amelia Staszowska1 \\ ${ }^{1}$ Lublin University of Technology, Faculty of Environmental Engineering, Nadbystrzycka 40b, 20-618 Lublin, Poland \\ ${ }^{2}$ Verano, Vetterów 7a, 20-277 Lublin, Poland
}

\begin{abstract}
The study presents the capabilities of the AutoCad CFD 2016 program as an auxiliary tool in the design of indoor air purification devices. The purpose of this work was to verify the location of UVC lamps and the elements enabling equal distribution of the air in the sterilisation module. The analysis was carried out in two-dimensional space. Three air streams of 100, 200 and $300 \mathrm{~m}^{3} / \mathrm{h}$ were assumed. The research considered the construction of a module with three and four UVC lamps in different configurations and with the module being additionally equipped with an injector, a steering device, an injector and a stream obstructer. The results suggest that the equal air distribution in the module is guaranteed with the variation of 4 UVC lamps additionally equipped with the injector and steering device at the angle of $30^{\circ}$, as well as the variation with the injector and stream obstructer with the height of $9.5 \mathrm{~mm}$.
\end{abstract}

\section{Introduction}

Germicidal properties of ultraviolet radiation have been known for a long time. In 1877 Downes and Blunt observed that solar radiation contributed to the inhibition of germs development [1]. At first used mainly in medicine to disinfect devices and rooms, it has been afterwards applied to water and air sterilisation. The germicidal effect of ultraviolet radiation involves the damage of nucleic structures of germs, which makes them lose their ability to reproduce and spread diseases [2].

Numerous researches confirm that UVC radiation effectively inactivates viruses, bacteria cells and spores $[3,4,5,6,7,8,9]$. It is claimed that UVC radiation is more effective in eliminating spores, both pigmented and nonpigmented, than UVB (290-310 $\mathrm{nm}$ ) and UVA (320$400 \mathrm{~nm}$ ) radiation [10]. UVC lamps have also turned out to be more effective in purifying indoor air contaminated with fungi spores and vegetal bacterial cells $[11 ; 12 ; 13]$.

The range of 220-300 nanometres $(\mathrm{nm})$ is considered to be the most effective length range of ultraviolet waves used to eliminate microbiological pollutants, the highest effectiveness being estimated at $265 \mathrm{~nm}$. Ultraviolet light is produced with the use of electrical discharge in mercury vapour closed at low pressure in a tube made of quartz glass. This method is applied to the production of lamps with the wavelength of $253.7 \mathrm{~nm}$, which falls within the range of UVC radiation [14]. It was proven that UVC radiation or germicidal UVGI radiation is equally effective in deactivating bacteria, fungi, viruses and mycoplasmas $[15,16,17,18,19]$.

The use of ultraviolet radiation (UV) in air or surface disinfection in the range considered to be germicidal
(200-365 nm) is referred to as UVGI - ultraviolet germicidal irradiation.

Laboratory tests on UVGI in the field of air treatment started in the 1920s and demonstrated that elimination of airborne diseases was feasible. In the 1930s, UVGI was applied to the sterilisation of operating theatres and school ventilation systems, which significantly reduced the occurrence of measles [20]. However, the projects began to be imitated instead of designed for a particular use, which resulted in some failures. According to two professors from Pennsylvania State University (2000), the overview of current sector practises indicates that the information on UVGI system design does not include the details required by engineers to ensure the proper effectiveness [20]. Since the year 2000, most of UVGI installations have been dedicated to hospital rooms. Office buildings, schools, public and residential buildings constitute less than $3 \%$ of the market. Since the year 2006, UVGI system has been added to filters systems in ventilation and air conditioning systems in carriages and buses in Toronto, Tampa, Fort Worth, Miami-Dade, Jacksonville and subway carriages in New York. Even the producer of luxury cars, Lexus, launched in 2005 the optional selection of filters+UV package in order to combat bacteria, mould, and consequently fragrances [21].

\section{Methodology}

The subject of the analysis was authors' module for air disinfection equipped with UVC lamps (Fig. 1). The module is intended for channel heaters. The design and construction of UVC module were preceded by model tests which enabled the choice of the solution ensuring equal air distribution. The construction of a module with

${ }^{*}$ Corresponding author: s.dumala@ pollub.pl 
three and four UVC lamps in different configurations was included in the research, together with the module being additionally equipped with the injector and the steering device, the injector and the stream obstructer. Each variation was developed for the streams of 100 , 200 and $300 \mathrm{~m}^{3} / \mathrm{h}$.

AutoCad CFD 2016 program was used. The analysis was conducted in two-dimensional space. The following three streams of air were assumed: 100, 200 and 300 $\mathrm{m}^{3} / \mathrm{h}$. The air was placed in the channel with the values assumed above. The exhaust of the channel was unobstructed and subjected to a boundary condition of $\mathrm{P}=0 \mathrm{~Pa}$. The pressure in the system was equal to atmospheric pressure. The analysis was performed under steady state conditions. SST k-omega turbulence model was assumed due to the occurrence of turbulence air flow. The area of the mesh around UV lamps was densified and 6 boundary layers of the mesh were assumed. The accuracy of mesh assumptions were verified with the value of $\mathrm{Y}+<2$. Simulations were run until the stabilisation of pressure parameters, as well as the concurrence of the remaining simulation parameters were achieved. The following parameters were assumed in the simulations:

- airstream temperature: $20^{\circ} \mathrm{C}$ (Dirichlet condition),

- temperature of lamps surfaces: not recorded

- heat exchange between lamps and air: not analysed

- isothermal conditions.

- after the selection of the condition of $\mathrm{p}=0 \mathrm{~Pa}$ set at the exhaust of the model, the supply airstream was compared to the exhaust airstream in accordance with the mass preservation law.

- the initial density analysis of calculative mesh was conducted, which revealed that the increase of the number of mesh elements does not alter the results of simulation and the $\mathrm{Y}+$ values were $<2$ in this case. I performed simulations with the use of SST k-omega turbulence model. For this calculation model, one of the parameters proving the correctness of conducted simulation is dimensionless $\mathrm{Y}+$ value which should amount to $<2$ (quoted from Autodesk help).

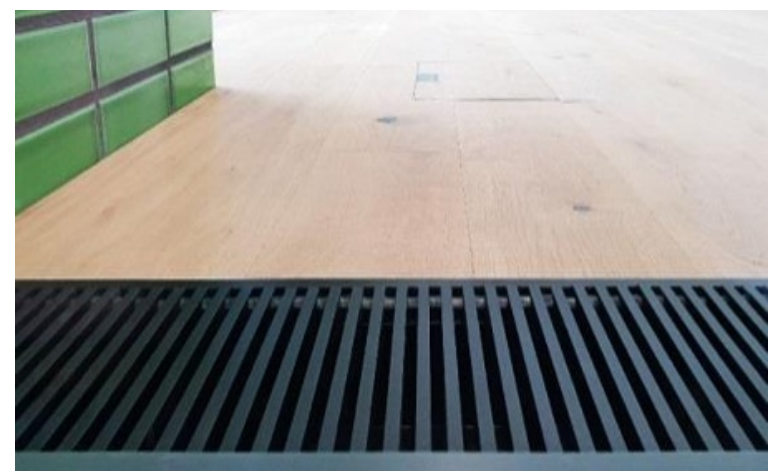

Fig. 1. Channel heater with a ventilator [22]
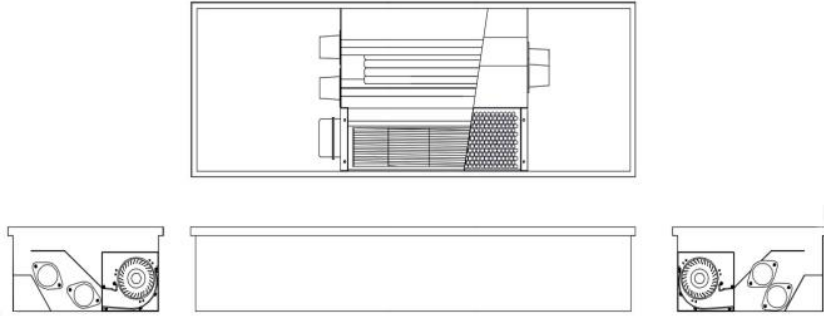

Fig. 2. Channel heater with a ventilator equipped with a module with UVC lamps.

\section{Results of computer simulations and discussion}

The results of selected simulations have been presented in Figures 3-8. The assumed comparison method of UV module construction in the channel heater was the establishment of the mesh of points located in the proper distance from the lamp system, and subsequently a table with air velocity for representative points. This enabled the estimation of air velocity distribution around the lamps and the choice of the solution with the lowest standard deviation for each representative point.

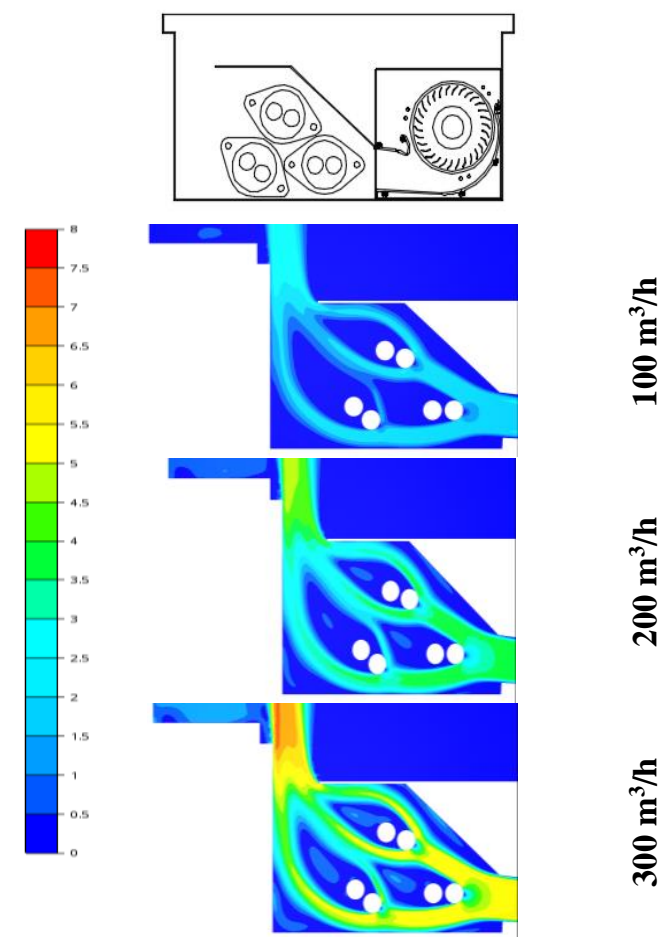

Fig. 3. Air velocity distribution in a module with three UVC lamps, for the air streams of 100,200 and $300 \mathrm{~m}^{3} / \mathrm{h}$.

The analysis showed that the equal air distribution in the module space is guaranteed by two variations: one with four UVC lamps equipped with an injector and a steering device - angle of $30^{\circ}$ (Fig. 8), and the other one with the injector and stream obstructer with the height of $9.5 \mathrm{~mm}$ (Fig. 7). 


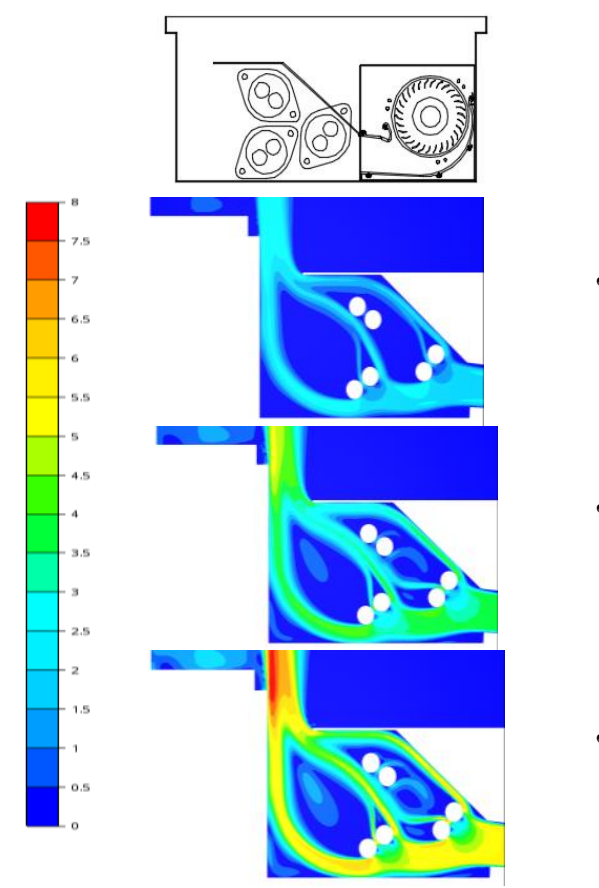

Fig. 4. Air velocity distribution in a module with three UVC lamps, for the air streams of 100,200 and $300 \mathrm{~m}^{3} / \mathrm{h}$ - change of lamp positions.

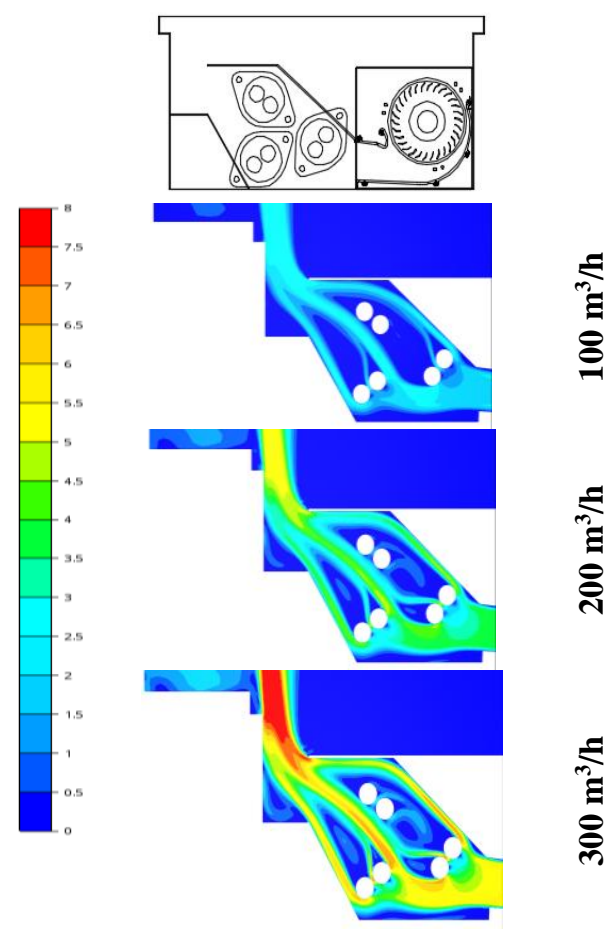

Fig. 5. Air velocity distribution in a module with three UVC lamps, for the air streams of 100, 200 and $300 \mathrm{~m}^{3} / \mathrm{h}-$ a module equipped with the injector.

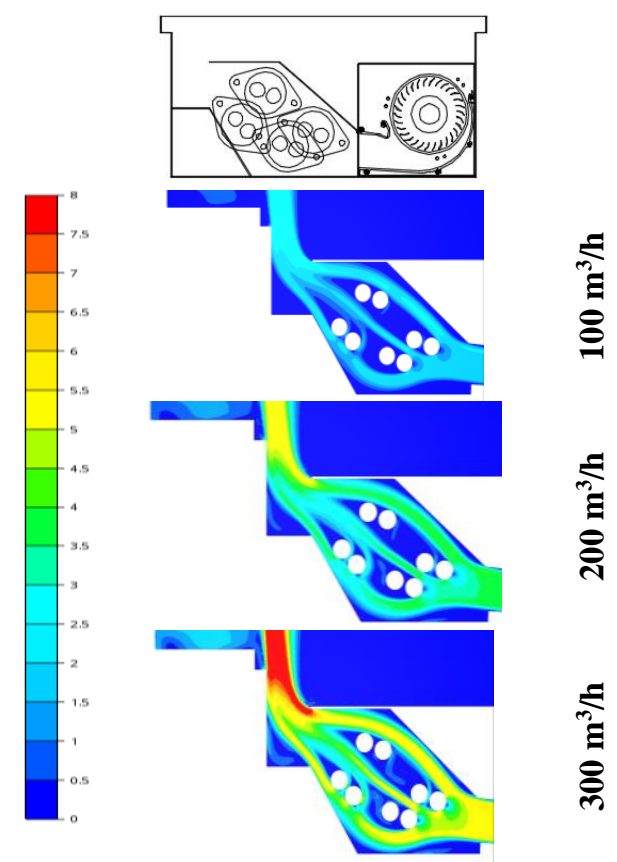

Fig. 6. Air velocity distribution in a module with four UVC lamps, for the air streams of 100,200 and $300 \mathrm{~m}^{3} / \mathrm{h}$ (lamps placed at the opposite sides of a model, two lamps at each side) - a module equipped with the injector.

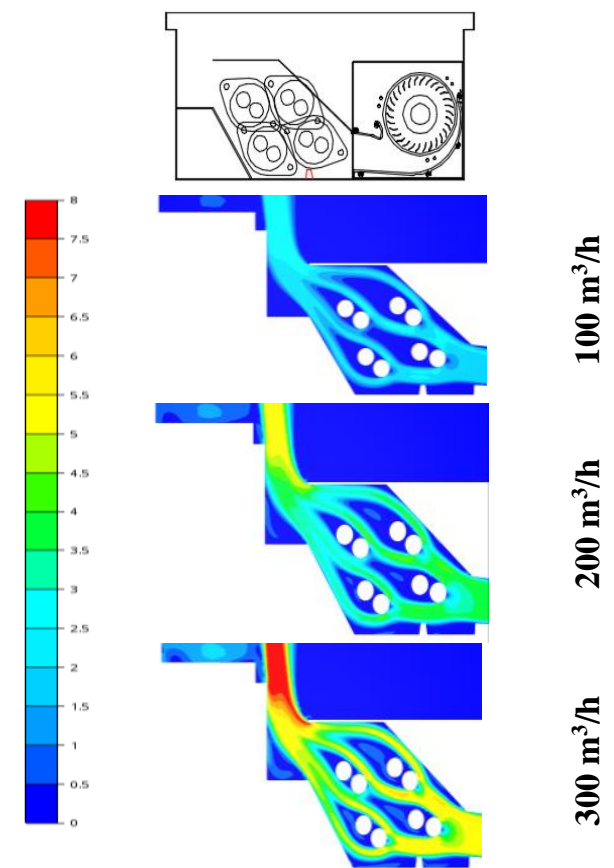

Fig. 7. Air velocity distribution in a module with four UVC lamps, for the air streams of 100, 200 and $300 \mathrm{~m}^{3} / \mathrm{h}$ (lamps placed at the opposite sides of a model, two lamps at each side) a module equipped with the injector and air stream obstructer with the height of $9.5 \mathrm{~mm}$. 


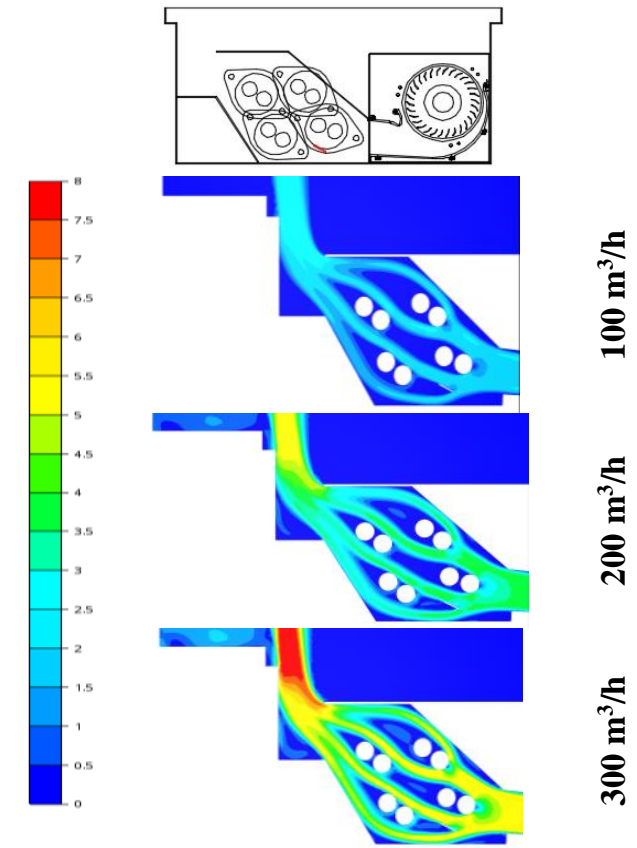

Fig. 8. Air velocity distribution in a module with four UVC lamps, for the air streams of 100, 200 and $300 \mathrm{~m}^{3} / \mathrm{h}$ (lamps placed at the opposite sides of a model, two lamps at each side) a module equipped with the injector and steering device angle of $30^{\circ}$.

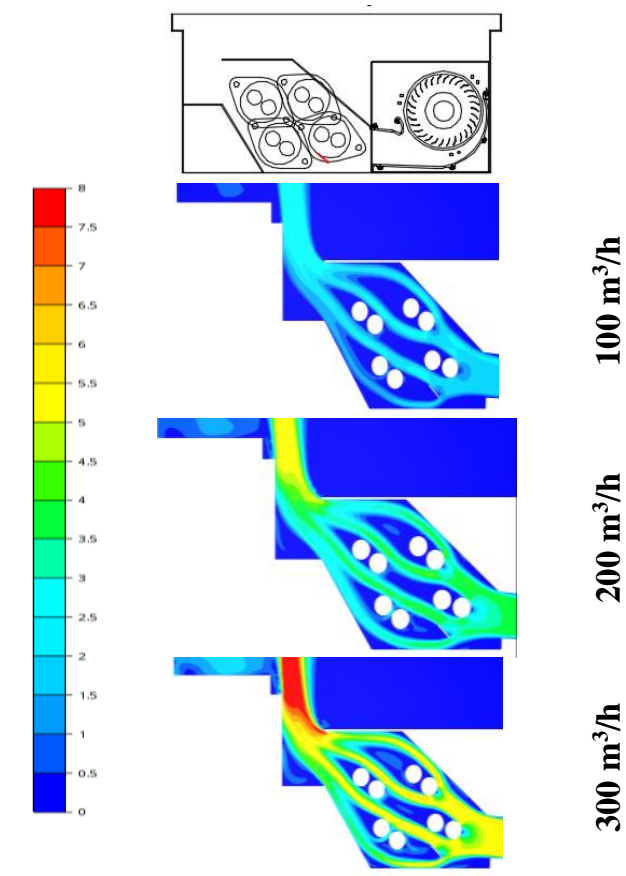

Fig. 9. Air velocity distribution in a module with four UVC lamps, for the air streams of 100, 200 and $300 \mathrm{~m}^{3} / \mathrm{h}$ (lamps placed at the opposite sides of a model, two lamps at each side) a module equipped with the injector and steering device angle of $40^{\circ}$.

Subsequently, the project documentation has been prepared that is required for construction of the prototype of the device, which was used in microbiological analyses for the evaluation of the effectiveness of air purification process.

\section{Conclusion}

Simulations run with AutoCad CFD program enabled to choose the solution ensuring equal air distribution in disinfecting module, regardless of the size of the air stream. The fact that the similar results have been obtained for two solutions enables verification of selected proposals in terms of production costs and the final price of the product.

\section{References}

1. N.G. Reed, Public Health Rep. 125 (2010)

2. I. Kałuska, Z. Stuglik, Rad. ster. sprz. med. W-wa (1996)

3. J.C. Chang, S.F. Ossoff, D.C. Lobe, M.H. Dorfman, C.M. Dumais, R.G. Qualls, J.D. Johnson, Appl. Environ. Microbiol. 49 (1985)

4. W.L. Nicholson, N. Munakata, G.Horneck, H.J. Melosh, P. Setlow, Microbiol. Mol. Biol. Rev. 64 (2000)

5. W.L. Nicholson, B. Galeano, Appl. Environ. Microbiol. 69 (2003)

6. P. Caillet-Fauquet, M. Di Giambattista, M. Draps, F. Sandras,T. Branckaert, Y. de Launoit, R. Laub, J. Virol. Methods. 118 (2004)

7. F. Taghipour, Water Res. 38, (2004)

8. E.R. Blatchley III, A. Meeusen, A.I. Aronson, L. Brewster, J. Environ. Eng. 9 (2005)

9. J. Koivunen, H. Heinonen-Tanski, Water. Res. 39 (2005)

10. R. Moeller, G. Horneck, R. Facius, E. Stackebrandt, FEMS Microbiol. Ecol. 51 (2005)

11. R.L. Riley, Infect. Contr. Hosp. Epidemiol. 15 (1994)

12. C.J. Cundith, C.R. Kerth, W.R. Hones, T.A. McCaskey, D.I. Kublers, J. Food Sci. 67 (2002)

13. E. Kujuvdzic, F. Matalkah, C.J. Howard, M. Hernanadez, S.L. Miller, J. Occup. Environ. Hyg. 3 (2006)

14. D. VanOsdell, K.K. Foarde, ARTI-21CR/61040030-01 (2002)

15. P.R. Morey, Amer. Soc. of Heat., Refri. and Air Condit. Eng. 10-25 (1988)

16. O.M. Lidwell, J. of Hos. Inf., 28 (1994)

17. M.A. Calvo, M. Agut, R.M. Calvo, J. Larrondo, Microbiol. 98 (1999)

18. T.A. Slieman, W.L. Nicholson, App. and Environ. Microbiol. 66 (2000)

19. J. Peccia, H.M. Werth, S. Miller, M. Hernandez, Aero. Scien. and Tech. 35 (2001)

20. W.J. Kowalski, W.P. Bahnfleth, ASHRAE Trans. 106 (2000)

21. M. Pollick, Sarasota Herald-Tribune (2006)

22. www.v-k.p. 